\title{
I Would like to, but I can't. An Online Survey on the Moral Challenges of German Farm Veterinarians
}

\section{Christian Dürnberger ${ }^{1} \mathbb{D}$}

Accepted: 16 October 2020 / Published online: 29 October 2020

(C) The Author(s) 2020

\begin{abstract}
The job of veterinarians is often described as morally challenging. This online survey $(n=123)$ investigated how farm veterinarians in Germany perceive these challenges. Most participants described their job in accordance with the literature: as a profession that regularly has to deal with morally difficult decisions. The majority assumed that their moral challenges were greater than the ones of small animal practitioners. The results indicate that the typical moral challenges are (a) situations in which the farm veterinarians are convinced to know what is morally right, however, specific external obstacles prevent them from implementing their convictions. Therefore, the central moral problem from the veterinarians' point of view can be described with the following words: "I would like to, but I can't." Other ideal types of moral challenges like (b) open ethical questions, (c) ethical dilemmas or (d) "duty vs. inclination" conflicts play a less prominent role. With regard to dealing with these challenges, the study shows that farm veterinarians are looking for exchange, for example with colleagues. Most participants see the current social debate about livestock farming as something that stresses them, arguing that their university's curriculum did not adequately prepare them to participate in these controversies.
\end{abstract}

Keywords Veterinary ethics $\cdot$ Moral conflicts $\cdot$ Farm veterinarians $\cdot$ ethics

\section{Introduction}

The job of veterinarians is embedded in a strained ethical structure, characterised at least by demands of animal patients, animal owners, professional obligations and society as a whole (Tannenbaum 1993; Rollin 2006; Morgan and McDonald 2007; Magalhães-Sant'Ana et al. 2016; Mullan and Fawcett 2017). This diagnosis is particularly true for veterinarians working in the field of livestock farming: Livestock

Christian Dürnberger

Christian.duernberger@vetmeduni.ac.at

1 Unit of Ethics and Human-Animal Studies, Messerli Research Institute, Vetmeduni Vienna,

Veterinärplatz 1, 1210 Vienna, Austria 
farming is an important element of the human food industry. However, today's western societies-Germany can be mentioned as a typical example-have an ambivalent relationship with the current animal husbandry (Boogard et al. 2011). While people appreciate low food prices and increased food safety (Boogard et al. 2008), they are increasingly concerned about animal welfare issues (Krystallis et al. 2009; Kayser and Spiller 2012; Busch et al. 2015; Clark et al. 2016; Bergstra et al. 2017; Special Eurobarometer 2018). For example: Confronted with images of common practices in current livestock farming, large parts of the German society judge them extremely negative (Boehm et al. 2010; Wildraut et al. 2015; Weible et al. 2016). Some voices call for the abolition of livestock farming: In the tradition of Regan (1983), who argued that non-human animals have specific moral rights because they have to be understood as "subjects-of-a-life", current German animal ethicists like Schmitz (2016) and NGOs oppose livestock farming per se, arguing that animals should not be kept for food production.

So, farm veterinarians not only have to weigh up the interests of animal patients, animal owners and other stakeholders, but the corresponding difficult decisions are taking place against the backdrop of the described social controversy. In other words: There are good reasons to describe the job of farm veterinarians as an epitome of an ethically challenging profession. However, there is still insufficient understanding of how farm veterinarians themselves perceive this situation. This research gap was the starting point of the present paper. The initial research questions were as follows: How often do farm veterinarians face moral challenges according to their own appraisal? How would they describe these moral challenges? Do they talk about them, or would they like to talk to someone about them? And finally, how do they experience the described social controversy about livestock farming?

\section{Methods}

The survey targeted veterinarians who are working (fully or partially) in the livestock sector in Germany. Using Google, 227 veterinarians or veterinary practices in the livestock sector in Germany were identified and invited by e-mail to take part in the online survey at www.umfrageonline.com. Beyond that, "MSD Tiergesundheit", the magazine "Der Hoftierarzt" as well as the Federal Association of Practising Veterinarians (Bundesverband Praktizierender Tierärzte e.V.) referred to the online survey. Participation in the study was voluntary and anonymous. No incentive was offered. The participants were informed that the results would be published anonymously.

The decision to carry out an online survey was taken for pragmatic reasons: Potential participants live all over Germany and have a tight schedule, making it difficult to invite them to semi-structured interviews or to visit them. The present online survey gave them the opportunity to be flexible in terms of time and place to answer the questions. The questionnaire consisted of three parts designed to collect data on the following issues: (a) demographic data (8 items: gender, age, working in which federal state, with which animals and since when, self-employed or employed, studied at which university and date of graduation); (b) moral challenges 
( 2 open and 12 closed questions); (c) future of veterinary medicine in the context of livestock farming ( 6 open and 6 closed questions). The results presented below focus on part (b), more precisely on the answers to the closed questions. These closed questions presented mostly statements requiring respondents to indicate the strength of their agreement or disagreement on a 6-point Likert scale: (1) I totally agree, (2) I agree, (3) I agree somewhat, (4) I disagree somewhat, (5) I disagree, (6) I totally disagree. The given statements were developed on the basis of ethics workshops with veterinarians.

The questionnaire was available online between 1 June and 30 September 2019. Answers to the open questions in the study were evaluated according to the method of qualitative content analysis, following Mayring (2015). The survey was conducted in German. When veterinarians are quoted in the text below, these statements were translated from German into English.

\section{Results}

\section{Demographic Data}

A total of 123 participants took part in the study (thereof approx. $51 \%$ female). The average age of the participants was 45.39 years. On average, the participants have been working as farm veterinarians for 16.39 years. Multiple selection was possible for the specific field of activity: Most of the participants (approx. 92\%) stated that they worked in the field of cattle farming; 33\% stated that they worked with pigs. About $50 \%$ of the participants stated that they were self-employed with salaried employees; about 35\% stated that they were employed, and about $13 \%$ were selfemployed without salaried employees. $89 \%$ of the participants have studied at German universities. The participants are working in twelve different German federal states. The "front runner" is Bavaria with 33\%, followed by Lower Saxony with $20 \%$ and North Rhine-Westphalia with 13.9\%. No significant differences were observed between demographic data and the answers presented below.

\section{Frequency of Moral Challenges}

The participants were asked how often they experienced morally challenging situations in their job. Thereby, the survey deliberately refrained from giving concrete examples or a given definition of "morally challenging situations". The farm veterinarians answered as follows $(n=122)$ : Never: $0.9 \%$; Rarely: $11.6 \%$; Sometimes: 40.2\%; Often: $41.1 \%$; Constantly: $6.3 \%$.

\section{Understanding Moral Challenges}

The participants were asked to describe the moral challenges of their job on the basis of given statements. The concrete question was: "To what extent do the following 
five statements describe the moral challenges of your job? Please indicate for each case the degree to which you agree/disagree." $(n=81)$.

\section{Exchange about Moral Challenges}

Asked how often they talk to someone about the moral challenges of their profession, the participants $(n=79)$ answered as follows: Never: $1.3 \%$; Rarely: $22.8 \%$; Sometimes: $38.0 \%$; Often: $31.6 \%$; Constantly: $6.3 \%$.

The study also asked whether the participating veterinarians would like to have a more intensive exchange about the moral challenges of their job $(n=79)$.

The participants also had the opportunity to answer an open question in this context: "Who would you most like to talk to about the moral problems of your profession?" (n=42).

The actors named most often were colleagues $(n=22)$. For example, one participant answered: "To colleagues who are in the same situation! For outsiders, some things are difficult to understand (especially when it comes to reports of animal welfare violations ...)." Another one wrote: "In the team we often talk about these things. Anyone who doesn't work in this sector doesn't understand the problems anyway." Another answer in this context was: I would like to talk about the moral problems of the job "with colleagues who, in my opinion, never make these moral considerations". Another participant wrote: Would I like to "exchange views with colleagues? That varies. There are some who very actively fight for animal protection. But behind us there is always someone who is quiet, cheaper and willing to take the money".

The study participants' second most frequent request in regard to exchange was with "politics" $(\mathrm{n}=17)$. Exemplary answers stated: I would like to talk to "those responsible in politics, especially at EU level (agricultural subsidies)", to those "people who made the laws", to those "people who have the power to change something", to politicians because they "should listen more often to the opinion of physicians including their moral burden and their pressure to comply with the animal protection law". The criticism becomes partly explicit here. For example, one participant wrote: I would like to talk to "politicians who have obviously lost their grip when it comes to compliance with the animal protection law and, thus, the German constitution". Another participant stated that he/she would like to "talk to competent politicians who obviously no longer exist".

The third most frequently mentioned actors were the "farmers" $(n=10)$. Veterinarians want to interact with farmers because they understand the problems, while "everyone else does not have access [to them]"; other answers stated that veterinarians wanted to talk to farmers because farmers "can make a difference".

\section{The Social Debate about Livestock Farming}

Livestock farming causes controversy these days, which also shapes the job of farm veterinarians. Against this background, the participants were confronted with statements concerning the social debate on farm animal husbandry $(n=79)$. 
The study also asked how the veterinarians see themselves in this area of tension $(n=76)$ : "In my role as a veterinarian in livestock farming, I sometimes feel like...".

\section{Discussion}

Most farm veterinarians describe their job in accordance with the literature: as morally challenging. Hardly any of the participants said that they were never or rarely confronted with morally challenging situations in their profession; about half of them even said that they often or constantly had to deal with such challenges. In doing so, the majority of farm veterinarians assume that their moral challenges are greater than those of their colleagues working in the small animal sector: Approximately $22 \%$ fully agree, approximately $32 \%$ agree and approximately $16 \%$ tend to agree with this statement (cf. Table 3).

The typical moral challenge of German farm veterinarians (from their point of view) is a situation in which they are convinced to know what is morally right, however, specific external obstacles prevent them from implementing their convictions. Therefore, the central moral problem from the veterinarians' point of view can be described with the following words: "I would like to, but I can't." Let us discuss this in detail: It seems appropriate to say that the corresponding literature focuses on "ethical dilemmas" when it comes to moral challenges of veterinarians (e.g. Morgan and McDonald 2007; Morgan 2009; Batchelor and McKeegan 2012; Kondrup et al. 2016; Rathwell-Deault et al. 2017; Kipperman et al. 2018), however, not every moral conflict is a dilemma situation. Against this background, the current survey tried to understand the moral challenges of farm veterinarians in more detail by requiring respondents to agree or disagree with ideal typical statements that were generated with reference to the history of philosophy. Ideal types are to be understood as one-sided intensification of certain aspects of an issue in order to obtain the most precise terms possible that are suitable for ordering the diversity of empirical phenomena (Weber 1968, 191). More precisely, the survey suggests distinguishing between at least four different ideal typical moral challenges (cf. Table 1). Statement (1) outlined what can be called an "open ethical question". In such a situation someone recognises a question as morally relevant (Pollmann 2014) without knowing what is the morally right thing to do. In contrast, statements (2) and (3) described implementation difficulties. In such situations, the acting person is convinced to know what is morally right, but there are external obstacles that prevent them from putting their convictions into practice. Statement (4) outlined an ethical dilemma. In such a situation there are good moral reasons to do $x$, but there are also good moral reasons to do $y$; however, you cannot do both at the same time. That means, whatever you decide, you are going to violate an important good (Williams 1978, 91ff.). Finally, statement (5) described a "duty vs. inclination" conflict (Kant, Groundwork of the Metaphysic of Morals, 396ff.): In such a situation, one knows what is the morally right thing to do, however, it is advantageous for their own interests to decide differently.

The results of the survey indicate that it does make sense to distinguish between these types and not speak, for example, indiscriminately about "ethical dilemmas", 


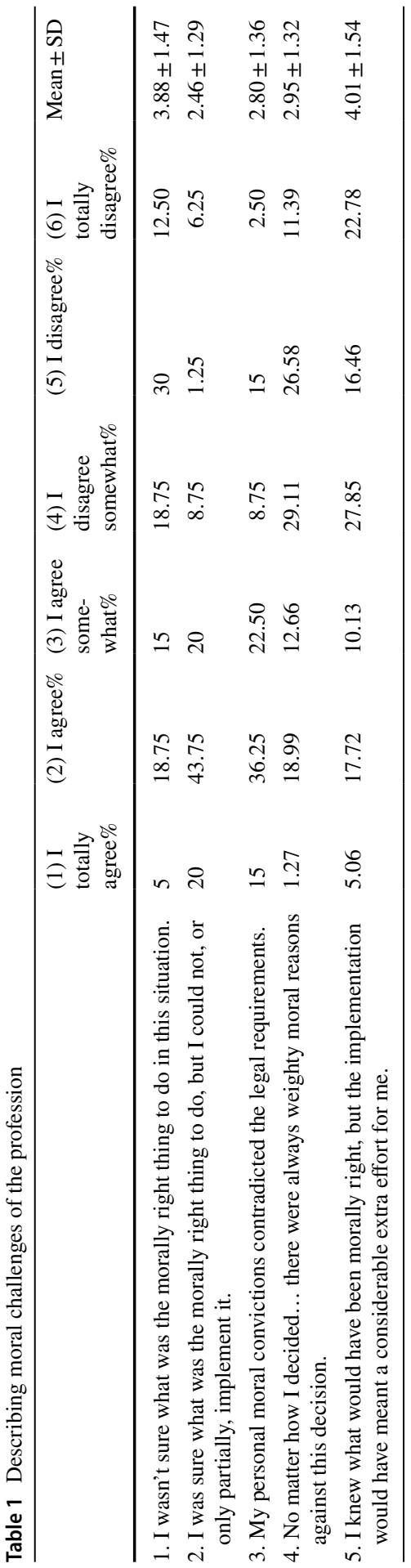


since the veterinarians themselves do distinguish: The given statements were evaluated differently. The statements describing implementation difficulties received the highest approval rate, followed by the statement describing an ethical dilemma, an open ethical question and, finally, duty vs. inclination situations. The top answer allows the thesis mentioned before: The typical moral challenge of German farm veterinarians is a situation in which external obstacles prevent them from implementing their convictions. This thesis leads to a conclusion that concerns, in particular, philosophers and ethicists since the results of this paper suggest that any ethics training programme for veterinarians should not only focus on ethical dilemmas or open ethical questions (like, for example, the concrete moral status of an animal in a specific situation), but rather make conflicts between external obstacles and personal convictions a vital issue. How should a veterinarian deal with this conflict? How do experienced professionals deal with this problem? And of course: Why is this type of conflict the decisive moral challenge at all?

To discuss the latter question, this paper proposes at least two possible interpretations: (a) The first interpretation could be called the "idealistic" one. In this interpretation, veterinarians are idealists who suffer from the fact that the conditions in livestock farming are sometimes worse than what veterinarians would like to see on the basis of their moral convictions. In this interpretation, the conditions in livestock farming lag behind the new demands concerning an adequate animal husbandry. Against this background, veterinarians would like to change or improve the system they are working in. (b) The second interpretation could be called the "provocative" one. Looking at the top answer, one could also draw a completely different conclusion: "If farm veterinarians suffer from the given conditions and this is their biggest moral challenge, probably the wrong people become farm veterinarians. They don't seem to know what they're getting into. They have wrong expectations. That's why they are suffering under the given conditions." The article does not specify which interpretation is more conclusive. In fact, there are probably other possible interpretations, but in any case, both provide a good starting point for intensive reflection and discussion in workshops with the farm veterinarians themselves.

In regard to the low approval rate for "duty vs. inclination", one aspect needs to be added: Statement (5) outlined a specific duty vs. inclination conflict in which the acting person knows what would be morally right but is more or less too lazy to do it. One could say the low approval rate is not surprising, because: Who likes to admit that they are lazy? A different nuance of the same type of conflict would probably have resulted in higher approval rates because the answers to the open questions show that such a "duty vs. inclination" conflict does play a role in the veterinarians' job-for example, in the following scenario: The farm veterinarian would like to help animals, for example by criticising the owner, however, the veterinarian has to weigh up between their moral convictions (to demand better conditions for the animals) and their own interests (not to lose the farmer as a customer).

Anyone who talks about moral conflicts has to think about their consequences: What are the effects when professionals regularly have to deal with morally difficult situations? Other professions-like the nursing sciences-have been asking this question for decades, developing the concept of moral distress (Jameton 1993)-a term that is now also being discussed in the veterinary context (Arbe Montoya et al. 
2019). In a broad definition, the term generally refers to any psychological distress that occurs as a result of the inability to adequately deal with a moral conflict (Monteverde 2013). Permanent moral distress is considered a major cause of emotional exhaustion, depression and burnout (Oh and Gastmans 2015) and of indifference in morally difficult situations (Epstein and Delgado 2010). The present study showed that most participants are indeed regularly confronted with moral challenges from their point of view, however, it does not indicate the extent to which the participants actually perceive these moral challenges as a source of moral distress. But there are indications that this is the case for at least some of them: For example, it was asked to what extent the participants agreed with the statement "The moral debates about livestock farming stress me". After all, about $14 \%$ totally agreed and 30\% agreed with this statement. Furthermore, the study addressed an aspect that is crucial in dealing with distress: To what extent do farm veterinarians talk about the moral challenges of their job? Do they seek exchange? The results indicate that the majority of farm veterinarians do talk about the moral problems of their job: Only about $1 \%$ said they never did, about $23 \%$ rarely, while $38 \%$ sometimes, about $32 \%$ often and about $6 \%$ constantly talk to somebody about these challenges. More than that: Many participants in the study expressed their desire for more intensive exchange with someone about these moral challenges (Table 2).

The emotional social debate about livestock farming was also the starting point for questioning the veterinarians' role: If livestock farming is currently such a controversial issue in society, in what role do the veterinarians see themselves? (Table 3) This question was examined on the basis of three pointed, polemical statements (Table 4): Do veterinarians see themselves as accomplices of a false system, as a kind of soldier (i.e. doing a job that is considered important by a large part of society, however, society does not want to know too much about the details of the job), or do they pragmatically describe their role as a control function in a system that focuses on economic aspects? The comparison of their own role with the one of a "soldier" got the highest approval. It is plausible to assume that criticism by society is implied in this answer: More appreciation is demanded and/or that citizens basically follow up with livestock farming and do not close their eyes.

When it comes to the question of whether farm veterinarians take pleasure in participating in the social debate about livestock farming, no clear picture emerges (cf. Table 3). Contrary, the results become clearer if farm veterinarians are asked to what extent their university's curriculum has adequately prepared them for these social controversies. The statement that their studies did not prepare them well for these controversies is fully agreed by about $35 \%$ and agreed by about $34 \%$ (cf. Table 3). This result can be interpreted as a desire for better training in this area.

The survey provides an insight into the moral challenges of farm veterinarians in Germany from their point of view. It thus creates an initial database that allows hypotheses to be framed, points towards further (representative) studies and generates new research questions. In doing so, the study has certain limitations: It does not provide information on the extent to which the participants represent the total population of German farm veterinarians. The described recruitment process, which focused on contacting veterinarians on the internet, only addressed veterinarians who have a website. Furthermore, a specific selection bias is possible, arguing that 


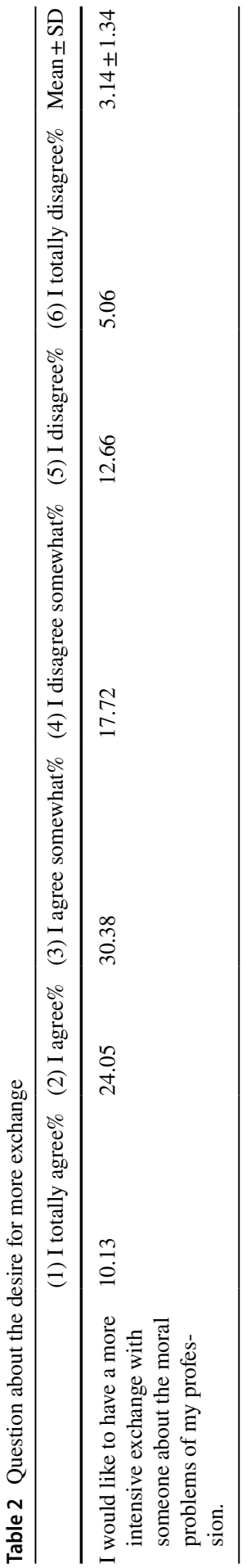




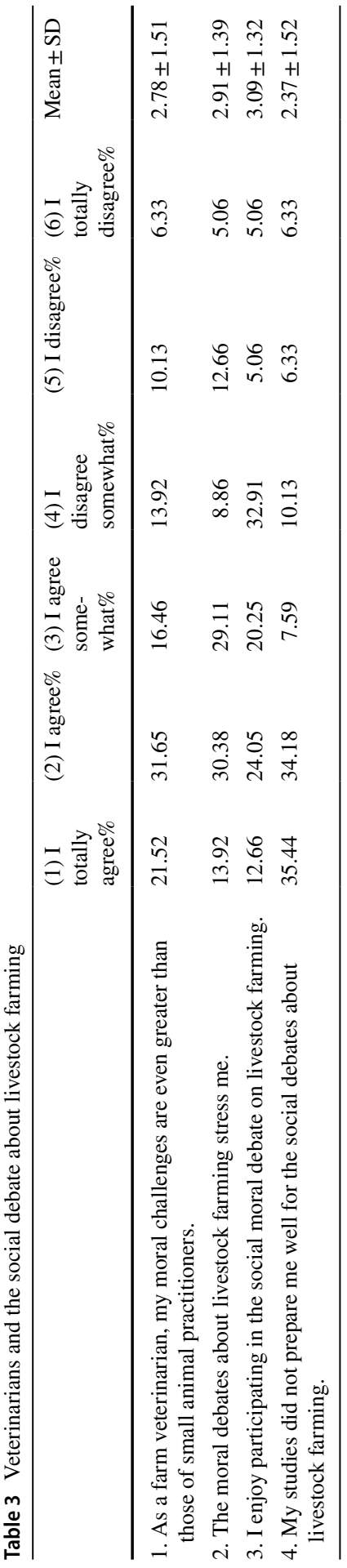




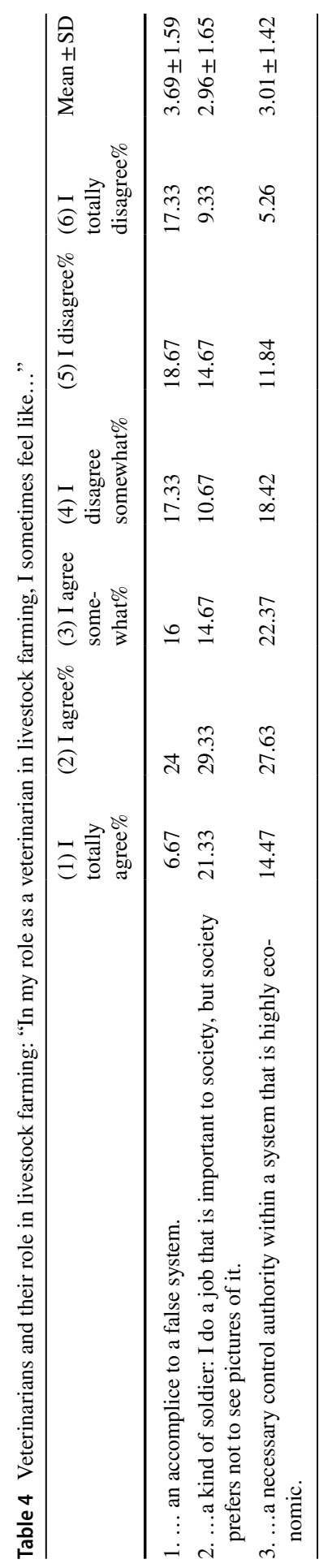


veterinarians who are more sensitive about "ethics" were maybe more willing to complete a questionnaire about the moral challenges of their job. In line with this, it cannot be excluded that the results of this study might represent the attitudes of veterinarians who are more sensitive about "ethics" and "moral challenges" than the general veterinary population. Finally, a topic like "moral challenges" poses the question to what extent the study partially documents socially desirable answers. Although such answers can never be completely ruled out, the study has tried to avoid socially desirable answers by formulating the questions and given statements neutrally and with restraint.

Acknowledgements I would like to thank all participants of the survey as well as MSD Tiergesundheit, "Der Hoftierarzt" and "Bundesverband Praktizierender Tierärzte e.V."

Funding Open access funding provided by University of Veterinary Medicine Vienna.

Availability of data and material The data discussed is presented in the paper in the section "results". The entire data can be made available on request.

\section{Compliance with Ethical Standards}

Conflict of interest No conflict of interest.

Open Access This article is licensed under a Creative Commons Attribution 4.0 International License, which permits use, sharing, adaptation, distribution and reproduction in any medium or format, as long as you give appropriate credit to the original author(s) and the source, provide a link to the Creative Commons licence, and indicate if changes were made. The images or other third party material in this article are included in the article's Creative Commons licence, unless indicated otherwise in a credit line to the material. If material is not included in the article's Creative Commons licence and your intended use is not permitted by statutory regulation or exceeds the permitted use, you will need to obtain permission directly from the copyright holder. To view a copy of this licence, visit http://creativecommons.org/licen ses/by/4.0/.

\section{References}

Arbe Montoya, A., Matthew, S. M., Hazel, S., \& McArthur, M. (2019). Moral distress in veterinarians. The Veterinary Record. https://doi.org/10.1007/s001090000086

Arzheimer, K. (2002). Politikverdrossenheit Bedeutung Verwendung und empirische Relevanz eines politikwissenschaftlichen Begriffes. Wiesbaden: Westdeutscher Verlag.

Batchelor, C. E. M., \& McKeegan, D. E. F. (2012). Survey of the frequency and perceived stressfulness of ethical dilemmas encountered in UK veterinary practice. The Veterinary Record. https://doi. org/10.1136/vr.100262

Bergstra, T. J., Hogeveen, H., \& Stassen, E. N. (2017). Attitudes of different stakeholders toward pig husbandry: a study to determine conflicting and matching attitudes toward animals, humans and the environment. Agriculture and Human Values, 34(2), 393-405.

Boehm, J., Kayser, M., \& Spiller, A. (2010). Two sides of the same coin? Analysis of the web-based social media with regard to the image of the agri-food sector in Germany. International Journal on Food System Dynamics, 3, 264-278.

Boogaard, B. K., Bock, B. B., Oosting, S. J., Wiskerke, J. S. C., \& van der Zijpp, A. J. (2011). Social Acceptance of Dairy Farming: The Ambivalence Between the Two Faces of Modernity. Journal of Agricultural and Environmental Ethics, 24(3), 259-282. 
Boogaard, B. K., Oosting, S. J., \& Bock, B. B. (2008). Defining sustainability as a socio-cultural concept: Citizen panels visiting dairy farms in the Netherlands. Livestock Science, 117, 24-33.

Busch, G., Gauly, S., \& Spiller, A. (2015). Wie wirken bilder aus der modernen tierhaltung der landwirtschaft auf verbraucher? neue ansätze aus dem bereich des neuromarketings. Schriftenreihe der Rentenbank, 31, 67-94.

Clark, B., Stewart, G. B., Panzone, L. A., Kyriazakis, I., \& Frewer, L. J. (2016). A systematic review of public attitudes, perceptions and behaviours towards production diseases associated with farm animal welfare. Journal of Agricultural and Environmental Ethics, 29(3), 455-478.

Epstein, E. G., \& Delgado, S. (2010). Understanding and addressing moral distress. OJIN, 15(3), 1.

Jameton, A. (1993). Dilemmas of moral distress: moral responsibility and nursing practice. AWHONNS Clin Issues Perinatal Womens Health Nurse, 4(4), 542-551.

Kant, I. (1967/1785). Grundlegung der Metaphysik der Sitten. Stuttgart: Reclam.

Kayser, M., \& Spiller, A. (2012). Das Image der verschiedenen Fleischarten aus KonsumentInnen-Sicht. In J. Hambrusch, C. Hoffmann, J. Kantelhardt, \& T. Oedel-Wieser (Eds.), Jahrbuch der österreichischen Gesellschaft für Agrarökonomie 21 (pp. 23-31). Wien: Facultas.

Kipperman, B., Morris, P., \& Rollin, B. (2018). Ethical dilemmas encountered by small animal veterinarians: characterisation, responses, consequences and beliefs regarding euthanasia. The Veterinary Record. https://doi.org/10.1136/vr.104619

Kondrup, S. V., Anhøj, K. P., Rødsgaard-Rosenbeck, C., Lund, T. B., Nissen, M. H., \& Sandøe, P. (2016). Veterinarian's dilemma: A study of how Danish small animal practitioners handle financially limited clients. The Veterinary Record. https://doi.org/10.1136/vr.103725

Krystallis, A., de Barcellos, M. D., Kügler, J. O., Verbeke, W., \& Grunert, K. G. (2009). Attitudes of European citizens towards pig production systems. Livestock Science, 126, 46-56.

Magalhães-Sant Ana, M., More, S. J., Morton, D. B., \& Hanlon, A. (2016). Ethical challenges facing veterinary professionals in Ireland: results from policy Delphi with vignette methodology. Veterinary Record. https://doi.org/10.1136/vr.103786

Mayring, P. (2015). Qualitative Inhaltsanalyse. Grundlagen und Techniken. 12th (revised). Weinheim: Beltz Verlag.

Monteverde, S. (2013). Pflegeethik und die Sorge um den Zugang zu Pflege. Pflege, 26(4), 271-280.

Morgan, C. A. (2009). Stepping up to the plate: Veterinarians, animal welfare and ethical dilemmas. Vancouver: University of British Columbia.

Morgan, C. A., \& McDonald, M. (2007). Ethical dilemmas in veterinary medicine. The Veterinary Clinics of North America. Small Animal Practice, 37(1), 165-179.

Mullan S., Fawcett A. (2017). Veterinary ethics: Navigating tough cases. 5m Publishing, Sheffield

Oh, Y., \& Gastmans, C. (2015). Moral distress experienced by nurses: A quantitative literature review. Nurse Ethics, 22(1), 15-31.

Pollmann, A. (2014). Was ist ein moralisches Problem? Information Philosophie, 3(2014), 15-25.

Rathwell-Deault, D., Godard, B., Frank, D., \& Doizé, B. (2017). Conceptualization of convenience euthanasia as an ethical dilemma for veterinarians in Quebec. Canadian Veterinary Journal, 58(3), $255-260$.

Regan, T. (1983). The Case for Animal Rights. Berkeley: University of California Press.

Rollin, B. (2006). An Introduction to Veterinary Medical Ethics: Theory And Cases. Oxford: Wiley-Blackwell.

Schmitz, F. (2016). Animal ethics and human institutions: Integrating animals into political theory. In R. Garner \& S. O’Sullivan (Eds.), The Political Turn in Animal Ethics (pp. 33-50). Lanham: Rowman $\&$ Littlefield.

Special Eurobarometer 473. Europeans, Agriculture and the CAP. Brussels, Directorate-General for Communication, 2018. Online available: https://data.europa.eu/euodp/data/dataset/S2161_88_4_473_ ENG (Date of access: 8 Feb. 2020)

Tannenbaum, J. (1993). Veterinary medical ethics: a focus of conflicting interests. J Soc Issues, 49, 143-156.

Weber, M. (1968). Gesammelte Aufsätze zur Wissenschaftslehre. Herausgegeben von Johannes Winckelmann. Tübingen: Mohr Siebeck.

Weible, D., Christoph-Schulz, I., Salamon, P., \& Zander, K. (2016). Citizens' perception of modern pig production in Germany: a mixed-method research approach. British Food Journal, 118(8), 2014-2032. 
Wildraut, C., Plesch, G., Härlen, I., Simons, J., Hartmann, M., Ziron, M., Mergenthaler, M. (2015). Multimethodische Bewertung von Schweinehaltungsverfahren durch Verbraucher anhand von Videos aus realen Schweineställen. Forschungsberichte des Fachbereichs Agrarwirtschaft Soest 36.

Williams, B. (1978). Ethical Consistency. J. Raz J (Ed.), Practical Reasoning (pp 91-109). Oxford University Press, Oxford

Publisher's Note Springer Nature remains neutral with regard to jurisdictional claims in published maps and institutional affiliations. 